\title{
Exposure to statins and risk of common cancers: a series of nested case-control studies
}

Yana Vinogradova*, Carol Coupland and Julia Hippisley-Cox

\section{Abstract}

Background: Many studies and meta-analyses have investigated the effects of statins on cancer incidence but without showing consistent effects.

Methods: A series of nested case-control studies was conducted covering 574 UK general practices within the QResearch database. Cases were patients with primary cancers diagnosed between 1998 and 2008. The associations between statin use and risk of ten site-specific cancers were estimated with conditional logistic regression adjusted for co-morbidities, smoking status, socio-economic status, and use of non-steroidal antiinflammatory drugs, cyclo-oxygenase-2 inhibitors and aspirin.

Results: 88125 cases and 362254 matched controls were analysed. The adjusted odds ratio for any statin use and cancer at any site were $1.01(95 \% \mathrm{Cl} 0.99$ to 1.04$)$. For haematological malignancies there was a significant reduced risk associated with any statin use (odds ratio $0.78,95 \% \mathrm{Cl} 0.71$ to 0.86 ). Prolonged (more than 4 years) use of statins was associated with a significantly increased risk of colorectal cancer (odds ratio $1.23,95 \% \mathrm{Cl} 1.10$ to 1.38), bladder cancer (odds ratio $1.29,95 \% \mathrm{Cl} 1.08$ to 1.54 ) and lung cancer (odds ratio $1.18,95 \% \mathrm{Cl} 1.05$ to 1.34 ). There were no significant associations with any other cancers.

Conclusion: In this large population-based case-control study, prolonged use of statins was not associated with an increased risk of cancer at any of the most common sites except for colorectal cancer, bladder cancer and lung cancer, while there was a reduced risk of haematological malignancies.

\section{Background}

Multiple randomised controlled trials have demonstrated the benefits of statins in improving survival for patients with ischaemic heart disease [1-5] and this has caused a substantial increase in statin use. While there are definite benefits from statins in reduction of mortality in high risk patients, uncertainties remain about whether statins might increase or decrease the risk of cancer[6-8]. This is important because statins are prescribed for extended periods to large numbers of patients.

The effect of long-term statin use is quite complex because the multiple properties of statins go beyond lipid lowering. There is evidence that statins increase endothelial dysfunction [9] and lower inflammatory markers[10] but it is still not clear whether they may affect the risk of cancer. Experimental data (primarily

\footnotetext{
*Correspondence: yana.vinogradova@nottingham.ac.uk

Division of Primary Care, $13^{\text {th }}$ floor, Tower Building, University Park, Nottingham, NG2 7RD, UK
}

using rats) have shown both carcinogenicity of statins [11] and no effect on carcinogenesis[12]. Some studies performed on human cancer cells in vitro have suggested that statins may be chemo-prophylactic against various types of cancer including colon[13] and breast cancer[14,15]. It has also been found that statins may suppress the growth of cancer cells in vitro by causing the cells to pause in the G1 phase of the mitotic cycle [16] and by increasing cell death[17].

There have been many randomised controlled trials of statins, but cancer has never been a primary outcome. The numbers of cancer cases have been relatively small and the duration of the trials too short to detect the effect of statins on cancer risk. The results from 35 randomised control trials have been summarised in a metaanalysis[18] reporting no association between statin use and overall cancer risk. However, the latest published results of another randomised controlled trial, not included in the meta-analysis, on the use of a combination of simvastatin and ezetimibe in patients with aortic 
stenosis demonstrated an increased risk for any cancer (105 vs.70, $\mathrm{P}=0.01)[19]$.

A number of observational studies were designed to assess risk of particular cancers in statin users and the results have been aggregated in a meta-analysis[7]. However, only some of the studies reported statin use of more than 5 years[20]. None of those findings were statistically significant except for one study reporting a decreased risk of prostate cancer, but based only on 42 statin users[21]. A recent study of statin use and ten common cancers[22] found a significantly reduced risk of haematological malignancies and an increased risk of endometrial cancer associated with more than 5 years of statin use.

All studies were smaller than the proposed one, and they were too dissimilar in their definitions of statin use to be analysed together: they either studied different types of statin or statin types were not specified. They also had differing lengths of intervention or follow-up, and included different confounding factors in their analyses.

Given the uncertainty regarding risk of cancer in association with statin usage, we designed a study to determine the risk for the most common incident cancers associated with taking statins including for prolonged periods using a very large population-based research database QRESEARCH. The size of the study has enabled us to adjust for use of other drugs and many potential confounding factors.

\section{Methods}

\subsection{Study design, data source and population}

We conducted a series of nested case control studies within a cohort of patients registered with practices in the UK contributing to the QRESEARCH database (version 20). The QResearch database (http://www.qresearch.org) is one of the largest general practice databases containing anonymised clinical records for over 11 million patients registered with 574 UK general practices. The information recorded on the database includes patient demographics (year of birth, sex, socio-demographic data derived from UK census 2001), characteristics (height, weight, smoking status), clinical diagnoses, symptoms, and prescribed medications including repeat prescriptions. The database has been validated by comparing birth rates, death rates, consultation rates, prevalence and mortality rates with other data sources, including the General Household Survey and the General Practice Research Database, and has demonstrated good levels of completeness and consistency $[23,24]$. Practices were included in the analysis only if they had complete data transmission until at least $1^{\text {st }}$ July 2008.

We identified an open cohort of patients registered with the study practices during the 10 year study period between 1st Jan 1998 and 1st July 2008. We then used
READ codes to select all cases aged between 30 and 100 years with a first record of any cancer in the patients' electronic records occurring during the study period. Each case was linked to 5 controls alive and registered with the practice at the time of diagnosis of the case and matched by age, sex, practice and calendar time. Controls were allocated an index date which was the date on which their matched case was first diagnosed with cancer.

\subsection{Exclusions}

Cases with secondary cancers (READ codes: B56, B57, B58) were excluded. Cases and controls with a diagnosis of any cancer before the index date were excluded. In addition, for breast cancer, we excluded cases and controls with any prior record of mastectomy or prescriptions for tamoxifen since they could be breast cancer cases without a recorded diagnosis in their record. To ensure completeness of exposure data we also excluded temporary residents and patients with fewer than 6 years of medical records before the index date for the main analysis - and fewer than 10 years for the further analysis.

\subsection{Primary outcomes}

We determined the risks for the most common cancers in the UK[25], comparing these for patients prescribed statins against those not prescribed the drugs. The investigated cancers and corresponding READ codes were: Breast cancer (women, B34), Prostate cancer (men, B46), Lung cancer (B22), Bladder cancer (B49), Haematological malignancies (B6), Gastric cancer (B11), Oesophageal cancer (B10), Colorectal cancer (B13, B14), Pancreatic cancer (B17) and Melanoma (B32). As haematological malignancies cover a range of diseases, possibly differentially affected by statins, we also investigated leukaemia (B63-B6z), lymphoma (B60-B62) and myeloma (B63) separately.

\subsection{Exposure variables}

Statin exposure was determined based on all prescriptions for statins until 1 year before the index date (date of diagnosis or equivalent date for controls). The drugs included were atorvastatin, pravastatin, fluvastatin, cerivastatin, rosuvastatin, and simvastatin. Prescriptions in the year before the index date were ignored because including these could lead to results being affected by reverse causality - prescribing in cases in this period might be the result of consultations relating to early cancer symptoms before the recorded diagnosis and this could attenuate any protective effect or exaggerate any harmful effect.

For the main analysis, we considered a 60-month period comprising statin prescriptions for the 13 to 72 
months prior to the index date. For the additional analysis, covering a follow-up of 10 years, the period considered was 98 months - for the 13 to 120 months prior to the index date.

Statin use was categorised in a number of ways. We considered a patient as a statin user if they had at least 2 prescriptions in the 60-month period (or the 98-month period for the 10-year analysis). We estimated the cumulative use of statins by extracting the duration of use for every prescription and, for groups of prescriptions with inter-prescription gaps of less than 60 days, we calculated overall course times from the start of the first prescription to the end of the last prescription. We then calculated cumulative use as the sum of all overall course times and for the main analysis categorized cumulative use for each patient as: no use; less than 12 months; 13 to 24 months; 25 to 36 months; 37 to 48 months; 49 to 60 months. A test for trend was performed using the actual number of months of use. For the further analysis, covering a follow-up period of 10 years, the categorisation of the time period for statin use was: no use; less than 12 months, 13 to 24 months, 25 to 48 months, 49 to 72 months, and more than 73 months.

If there were at least 2 prescriptions in the 60-month main study period (or in the 98-month additional study period), we conducted analyses for the following individual statin types: simvastatin, atorvastatin, cerivastatin, fluvastatin, pravastatin and rosuvastatin. For the most common types - simvastatin, atorvastatin and pravastatin - we also examined the effect of cumulative use on cancer risk.

Statin dosage was calculated as median dose across the observation time period, and was categorised as low, medium or high according to statin efficacy[26]. The effect of stopping statin usage on risk of cancer was investigated in the main study only by comparing the last prescription date in the study period with the date one year before the index date and categorising as: no statin use in the 13 to 72 months prior to the index date; still on statins; stopped statins 13 to 24 months before the index date; and stopped statins 25 or more months prior to the index date.

\subsection{Potential confounding variables}

We adjusted for variables which are established cancer risk factors: diabetes[27], rheumatoid arthritis[28], hypertension[29] and body mass index (< 25, 25-29.99, $\geq 30 \mathrm{~kg} / \mathrm{m}^{2}$ )[30], if recorded at least 1 year before the index date, and for smoking status (non-smoker, exsmoker, current smoker) and individual Townsend deprivation score (measure of socio-economic status, in fifths), if recorded before the index date. The Townsend score was based on 2001 postcode-related census data, with higher scores indicating greater level of material deprivation and was used because there is a link between deprivation and incidence of some types of cancer[31]. We adjusted for cardiovascular disease as the main reason for statin therapy. For breast cancer we also accounted for any previous benign breast disease (fibrocystic disease, intraductal papilloma, fibroadenoma) and for family history of breast cancer. For colorectal cancer, additional confounders considered were colitis and Crohn's disease.

We also adjusted for use of traditional non steroidal anti-inflammatory drugs, cyclooxygenase- 2 inhibitors and aspirin, as several studies have found protective effects for non-steroidal anti-inflammatory drugs and aspirin on various types of cancer[32,33], in particular on colorectal cancer[33]. We categorised the number of prescriptions for these drugs in the 60-month main study period as: none; 1 to $12 ; 13$ to 24 ; and 25 or more (adding 25 to 48 and 49 or more for the 98 -month additional study period); and adjusted for those categories in assessing cancer risk. We also included in the analyses use of other medications likely to increase the risk of cancer (hormone replacement therapy and oral contraceptive use for breast cancer analysis[34]) if there were at least 2 prescriptions of a drug in the 60-month main study period or 98-month additional study period.

\subsection{Statistical analysis}

We used conditional logistic regression to estimate odds ratios with 95\% confidence intervals for cancer overall and each of the specific cancer sites. As body mass index, smoking status and Townsend deprivation score may be important confounders and have a certain amount of missing data, we used multiple imputation for the missing values[35,36]. We used the ICE procedure in STATA to obtain 5 imputed datasets and applied Rubin's rules to combine effect estimates and estimate standard errors to allow for uncertainty caused by the missing data. We repeated the imputation procedure for each type of cancer separately.

The initial analysis model determined the unadjusted odds ratios for each cancer associated with statin prescriptions according to: any use of statins in the 60month study period (at least 2 prescriptions in the 13 to 72 months before the index date); cumulative duration of use; and the median prescribed dose. A multivariate model determined the odds ratio for each cancer associated with statin prescriptions adjusted for the potential confounding effects of variables listed above. For comparison with the analyses using imputed data for smoking status and body mass index, we also ran complete case analyses including only cases and controls with complete data as well as analyses using indicator variables for missing categories of smoking, deprivation and body mass index. 
We used all the available data on the QResearch database so did not do a pre-study sample size calculation. According to post-hoc calculation, in order to detect an odds ratio of 0.8 (or 1.2 ) with $80 \%$ power at $1 \%$ significance for an exposure that occurs in 15\% of controls a sample of 2685 cases (or 3424 cases) would be needed. We checked that we had sufficient power for analysis of the six commoner cancers. STATA v 10 was used for all the analyses. We used a $1 \%$ significance level to account for the multiple outcomes.

\section{Results}

Overall there were 118,780 patients with a recorded diagnosis of cancer at any site within the study period. 3,810 patients had diagnoses of secondary cancers so were removed from the analysis. Thirty six patients were coded with cancers applicable only to the other gender and were also removed. For breast cancer 370 cases and 302 controls with a previous history of mastectomy were excluded as were a further 685 cases and 471 controls with a previous history of tamoxifen use. This left a total of 113,879 patients with a first diagnosis of cancer during the study period and 568,958 controls. After removing patients with less than 6 years of medical records there were 88,125 cases of primary cancer matched with 362,254 controls. Eighty-one percent of cases and $71 \%$ of controls also had complete data for 10 years of follow-up. The proportions of cases with different types of cancer were similar to proportions in cancer registration statistics in England for 2003[37] for patients older than 30 years.

\subsection{Baseline characteristics}

Table 1 shows baseline characteristics for cases of cancer at any site and their matched controls. Fifty-three percent of the cases were men; the median age at diagnosis was 69 years (interquartile range: 60 to 77 ). Seventy six percent of cases and $73 \%$ of controls had complete data for body mass index, smoking status and Townsend deprivation score.

Cases and controls had similar patterns of co-morbidity except for diabetes $(8.1 \%$ in cases vs. $7.4 \%$ in controls). The difference in proportion of diabetic patients was most marked in pancreatic cancer cases $(12.7 \%$ vs. $8.3 \%$ in controls).

\subsection{Statin exposure}

Overall $15.5 \%$ of cases and $15.1 \%$ of controls had at least 2 statin prescriptions between 13 to 72 months prior to the index date. Most of the statin users (95\% of cases and controls) had statin prescriptions for more than a year. Median numbers of scripts for statin users were 19 (interquartile ranges, 9 to 32) for cases and for controls. Median numbers of months on statin were 28 for cases and controls (interquartile ranges, 12 to 50 for cases and 12 to 49 for controls).

The most frequently prescribed statins were simvastatin $(9.2 \%$ of cases and $9.0 \%$ of controls), atorvastatin (6.1\% of cases and $5.9 \%$ of controls) and pravastatin (1.6\% of cases and controls). The other statins were prescribed to less than $1 \%$ of the population. Very few atorvastatin users had low dose prescriptions (3 cases and 28 controls) and few pravastatin users had high dose prescriptions (4 cases and 12 controls). Simvastatin dosage was distributed evenly. Long-term statin use was associated with higher dose: in patients prescribed statins for more than 4 years, $42 \%$ of cases and $43 \%$ controls were on high doses compared with $31 \%$ cases and $31 \%$ controls on high doses in patients prescribed statins for less than 4 years.

The results of the main analyses, based on patients with at least 6 years of medical records, are shown in Tables 2, 3, 4 and Figure 1. Table 5 shows the odds ratios for each cancer according to cumulative duration of statin use in patients with at least 10 years of medical records.

\subsubsection{Cancer of any site}

The analysis for overall risk of cancer (at any site) did not show a significant association with any statin use (Table 2). Patients with a cumulative prescription duration of more than one year had a similar risk of cancer of any site compared with patients with no statin prescriptions (adjusted odds ratio (AOR) 1.02, 95\%CI 0.99 to 1.05). Analyses of trends for duration of use (Table 3) and dosage, as well as analysis of use of individual statins (Table 4), did not show any effect of statins on overall risk of cancer.

\subsubsection{Colorectal cancer}

There was no overall increase of colorectal cancer risk in statin users (AOR 1.07, 95\% CI 1.00 to $1.15, \mathrm{P}=$ 0.056), with a slight association for patients with prescriptions for more than a year $(\mathrm{AOR}=1.09,95 \% \mathrm{CI}$ 1.01 to $1.18, \mathrm{P}=0.036)$, which was not however statistically significant at $\mathrm{P}<0.01$. Further analysis showed a significant association with duration of use of statins $\left(P_{\text {trend }}=0.001\right)$, with a $23 \%$ increased risk for 49 to 60 months of use of (AOR 1.23, 95\%CI 1.10 to 1.38) compared with no use. The analysis of the median prescribed dose of statins revealed a significant association with an $18 \%$ increased risk on high dose of statin (AOR $1.18,95 \%$ CI 1.07 to $1.31, \mathrm{P}=0.001$ ).

Analyses of individual statins showed an association between colorectal cancer and atorvastatin $\left(\mathrm{P}_{\text {trend }}=\right.$ 0.001 ), with an increased risk of colorectal cancer associated with atorvastatin use of 4 or more years (AOR $1.51,95 \%$ CI 1.24 to 1.83 ).

The risk of colorectal cancer was not significantly increased for patients who stopped taking statins more 
Table 1 Baseline characteristics for all cases with primary cancer and their matched controls with at least 6 years of medical records

\begin{tabular}{|c|c|c|}
\hline & Cases $(\mathrm{N}=88125)$ & Controls $(\mathrm{N}=362254)$ \\
\hline \multicolumn{3}{|l|}{ Sex } \\
\hline female & $41749(47.4)$ & $170173(47.0)$ \\
\hline male & $46376(52.6)$ & $192081(53.0)$ \\
\hline \multicolumn{3}{|l|}{ Age band (years) } \\
\hline $30-54$ & $13151(14.9)$ & $49906(13.8)$ \\
\hline $55-64$ & $19638(22.3)$ & $80107(22.1)$ \\
\hline $65-74$ & $26758(30.4)$ & $111698(30.8)$ \\
\hline $75-84$ & $25013(28.4)$ & $106278(29.3)$ \\
\hline $85+$ & $3565(4.0)$ & $14265(3.9)$ \\
\hline \multicolumn{3}{|l|}{ Deprivation } \\
\hline Townsend quintile 1, most affluent & $22072(25.0)$ & $92287(25.5)$ \\
\hline Townsend quintile 2 & $18998(21.6)$ & $79067(21.8)$ \\
\hline Townsend quintile 3 & $17338(19.7)$ & $71358(19.7)$ \\
\hline Townsend quintile 4 & $15325(17.4)$ & $61767(17.1)$ \\
\hline Townsend quintile 5, most deprived & $11896(13.5)$ & $45971(12.7)$ \\
\hline Townsend missing & $2496(2.8)$ & $11804(3.3)$ \\
\hline \multicolumn{3}{|l|}{ Body mass index $\left(\mathrm{kg} / \mathrm{m}^{2}\right)$} \\
\hline $15-24$ & $26721(30.3)$ & $105883(29.2)$ \\
\hline $25-29$ & $27285(31.0)$ & $108803(30.0)$ \\
\hline $30-49$ & $12922(14.7)$ & $51413(14.2)$ \\
\hline not recorded & $21197(24.1)$ & $96155(26.5)$ \\
\hline \multicolumn{3}{|l|}{ Smoking status } \\
\hline non-smoker & $54307(61.6)$ & $233135(64.4)$ \\
\hline ex-smoker & 7567 (8.6) & $23842(6.6)$ \\
\hline current smoker & $17275(19.6)$ & $54869(15.1)$ \\
\hline not recorded & $8976(10.2)$ & $50408(13.9)$ \\
\hline \multicolumn{3}{|l|}{ Co-morbidities } \\
\hline Cardiovascular disease & $14278(16.2)$ & $58123(16.0)$ \\
\hline Diabetes & $7115(8.1)$ & $26802(7.4)$ \\
\hline Hypertension & $27104(30.8)$ & $109797(30.3)$ \\
\hline Osteoarthritis & $12807(14.5)$ & $52586(14.5)$ \\
\hline Rheumatoid arthritis & $1310(1.5)$ & $5132(1.4)$ \\
\hline Colitis $^{1}$ & $124(1.1)$ & $293(0.6)$ \\
\hline Crohn's disease $^{1}$ & $28(0.2)$ & $109(0.2)$ \\
\hline Benign breast disease $^{2}$ & $1094(7.0)$ & $2937(4.7)$ \\
\hline Family history of breast cancer $^{2}$ & $539(3.4)$ & $1249(2.0)$ \\
\hline \multicolumn{3}{|l|}{ Medications (in previous 13-72 months) } \\
\hline NSAID & $35697(40.5)$ & $140642(38.8)$ \\
\hline COX2 inhibitors & $6901(7.8)$ & $26974(7.4)$ \\
\hline Aspirin & $19895(22.6)$ & $79067(21.8)$ \\
\hline Hormone replace therapy ${ }^{2}$ & $3289(21.0)$ & $10973(17.4)$ \\
\hline Oral contraceptive pill ${ }^{2}$ & 523 (3.3) & $1638(2.6)$ \\
\hline
\end{tabular}

\footnotetext{
1) Based only on cases with colorectal cancer and their controls

2) Based only on female cases with breast cancer and their controls
} 
Table 2 Use of statins in cases and controls in 13 to 72 months prior the index date by cancer site (in cases and matched controls with at least 6 years of medical records)

\begin{tabular}{|c|c|c|c|c|c|c|c|c|c|}
\hline \multirow{2}{*}{$\begin{array}{l}\text { Cancer } \\
\text { breast }+\end{array}$} & \multirow{2}{*}{$\begin{array}{c}\begin{array}{c}\text { Total number } \\
\text { of cases }\end{array} \\
15666\end{array}$} & \multirow{2}{*}{$\begin{array}{c}\begin{array}{c}\text { Total number } \\
\text { of controls }\end{array} \\
62938\end{array}$} & \multirow{2}{*}{$\begin{array}{c}\mathbf{N} \text { of statin users } \\
\text { in cases (\%) }\end{array}$} & \multirow{2}{*}{$\begin{array}{c}\mathbf{N} \text { of statin users in } \\
\text { controls (\%) }\end{array}$} & \multicolumn{2}{|c|}{$\begin{array}{c}\text { Unadjusted OR (95\% } \\
\mathrm{Cl})\end{array}$} & \multicolumn{2}{|c|}{$\begin{array}{c}\text { Adjusted }^{\#} \text { OR }(95 \% \\
\mathrm{Cl})\end{array}$} & \multirow{2}{*}{$\begin{array}{c}\begin{array}{c}\text { P- } \\
\text { value }\end{array} \\
0.993\end{array}$} \\
\hline & & & & & 0.98 & (0.92 to 1.04 ) & 1.00 & (0.93 to 1.08 ) & \\
\hline prostate & 14764 & 61853 & 2774 (18.8) & 11508 (18.6) & 1.03 & (0.98 to 1.08 ) & 1.08 & (1.01 to 1.14$)$ & 0.016 \\
\hline colorectal $\neq$ & 11749 & 48624 & $2000(17.0)$ & $7770(16.0)$ & 1.12 & (1.06 to 1.19 ) & 1.07 & (1.00 to 1.15$)$ & 0.056 \\
\hline lung & 10163 & 42415 & 1998 (19.7) & 7621 (18.0) & 1.16 & (1.09 to 1.23 ) & 1.07 & (0.99 to 1.16$)$ & 0.095 \\
\hline blood & 7185 & 29162 & $973(13.5)$ & 4339 (14.9) & 0.91 & (0.84 to 0.99 ) & 0.78 & (0.71 to 0.86$)$ & $<0.001$ \\
\hline bladder & 4227 & 17559 & $856(20.3)$ & $3125(17.8)$ & 1.23 & (1.12 to 1.34$)$ & 1.15 & (1.03 to 1.29$)$ & 0.012 \\
\hline skin & 3249 & 13115 & $433(13.3)$ & 1675 (12.8) & 1.12 & (0.99 to 1.26$)$ & 1.08 & (0.93 to 1.26$)$ & 0.292 \\
\hline oesophagus & 3159 & 13041 & $496(15.7)$ & $2106(16.1)$ & 0.97 & (0.87 to 1.09 ) & 0.88 & (0.77 to 1.01$)$ & 0.072 \\
\hline pancreas & 2110 & 8762 & $365(17.3)$ & $1397(15.9)$ & 1.15 & (1.01 to 1.32 ) & 0.96 & (0.82 to 1.14 ) & 0.671 \\
\hline stomach & 1992 & 8279 & $322(16.2)$ & $1363(16.5)$ & 1.00 & (0.87 to 1.16$)$ & 0.86 & (0.72 to 1.02$)$ & 0.078 \\
\hline All cancers & 88125 & 362254 & $13621(15.5)$ & $54606(15.1)$ & 1.07 & (1.05 to 1.09 ) & 1.01 & (0.99 to 1.04$)$ & 0.280 \\
\hline
\end{tabular}

\# Adjusted for Townsend quintile, body mass index, smoking status, myocardial infarction, coronary heart disease, diabetes, hypertension, stroke, rheumatoid arthritis, use of NSAIDs, Cox2-inhibitors, aspirin

† Also adjusted for family history of breast cancer, use of oral contraceptives, hormone-replace therapy

‡ Also adjusted for colitis and Crohn's disease

than 2 years before the index date (AOR 1.03, 95\%CI 0.81 to 1.31 ).

The increased risk of colorectal cancer associated with longer duration of statin use found in patients with at least 6 years of medical records was not supported by the trend test of months on medication in patients with at least 10 years of medical records $(\mathrm{p}=0.069)$.

\subsubsection{Bladder cancer}

For bladder cancer, there was a borderline 15\% increased risk of cancer associated with any use of statins $(\mathrm{P}=0.012)$ and a $16 \%$ increased risk associated with more than one year's use $(P=0.018)$, but these were not statistically significant. For patients with more than 48 months of statin use, risk of bladder cancer was $29 \%$ higher (AOR, 1.29, 95\% 1.08 to 1.54 , P $=0.006)$ but the trend test for duration was not statistically significant $\left(\mathrm{P}_{\text {trend }}=0.014\right)$. No particular type of statin was significantly associated with an increased risk. The risk of bladder cancer was not significantly increased in patients who stopped taking statins more

Table 3 Cumulative duration of statin use in cases and controls in $\mathbf{1 3}$ to $\mathbf{7 2}$ months prior to the index date by cancer site (in cases and matched controls with at least 6 years of medical records)

\begin{tabular}{|c|c|c|c|c|c|c|c|c|c|}
\hline \multirow[b]{2}{*}{ cancer } & \multicolumn{2}{|c|}{ Less than 12 months } & \multicolumn{2}{|c|}{13 to 24 months } & \multicolumn{2}{|c|}{25 to 48 months } & \multicolumn{3}{|c|}{49 months and more } \\
\hline & $\begin{array}{l}\text { Cases/ } \\
\text { Controls }\end{array}$ & $\begin{array}{l}\text { Adjusted Odds } \\
\text { ratio }(95 \% \mathrm{Cl})\end{array}$ & $\begin{array}{l}\text { Cases/ } \\
\text { Controls }\end{array}$ & & $\begin{array}{l}\text { Cases/ } \\
\text { Controls }\end{array}$ & & $\begin{array}{l}\text { Cases/ } \\
\text { Controls }\end{array}$ & & $\begin{array}{l}\mathrm{P}-* \\
\text { value }\end{array}$ \\
\hline east + & & 90 to 1.13$)$ & 289/1292 & 0.93 (0.81 to 1.07$)$ & $430 / 1685$ & $1.07(0.95$ to 1.21$)$ & $329 / 1439$ & 0.95 (0.83 to 1.09$)$ & 0.719 \\
\hline rostate & $668 / 2784$ & 1.05 (0.95 to 1.15$)$ & $560 / 2187$ & $1.14(1.03$ to 1.26$)$ & $796 / 3295$ & 1.09 (0.99 to 1.19$)$ & $750 / 3242$ & 1.05 (0.95 to 1.16$)$ & 0.084 \\
\hline colorectalf & $525 / 2038$ & 1.05 (0.95 to 1.17$)$ & $400 / 1595$ & 1.04 (0.92 to 1.17$)$ & $539 / 2230$ & $1.02(0.92$ to 1.14$)$ & $536 / 1907$ & 1.23 (1.10 to 1.38$)$ & 0.002 \\
\hline lung & $485 / 1857$ & $1.02(0.90$ to 1.15$)$ & $406 / 1478$ & 1.11 (0.97 to 1.27$)$ & $549 / 2233$ & 1.01 (0.90 to 1.14$)$ & $558 / 2053$ & 1.18 (1.05 to 1.34$)$ & 0.013 \\
\hline blood & $255 / 1082$ & 0.84 (0.72 to 0.98$)$ & $201 / 860$ & 0.81 (0.68 to 0.96 ) & $277 / 1307$ & 0.73 (0.63 to 0.84 ) & $240 / 1090$ & 0.76 (0.65 to 0.89 ) & $\begin{array}{l}< \\
0.001\end{array}$ \\
\hline bladder & 209/785 & 1.13 (0.95 to 1.34$)$ & $174 / 611$ & 1.18 (0.98 to 1.42 ) & 240/952 & 1.06 (0.90 to 1.25$)$ & 233/777 & 1.29 (1.08 to 1.54$)$ & 0.014 \\
\hline skin & $120 / 422$ & 1.19 (0.95 to 1.49$)$ & $61 / 347$ & 0.74 (0.55 to 0.99$)$ & $141 / 474$ & 1.23 (0.99 to 1.54$)$ & $111 / 432$ & 1.08 (0.84 to 1.39$)$ & 0.373 \\
\hline besophagus & $126 / 571$ & 0.82 (0.67 to 1.02$)$ & $97 / 394$ & 0.91 (0.71 to 1.17 ) & $128 / 601$ & 0.82 (0.66 to 1.02 ) & $145 / 540$ & 1.04 (0.83 to 1.30$)$ & 0.705 \\
\hline pancreas & $87 / 367$ & 0.85 (0.66 to 1.10$)$ & $73 / 269$ & 1.02 (0.76 to 1.36$)$ & $113 / 390$ & 1.09 (0.86 to 1.40$)$ & $92 / 371$ & 0.97 (0.74 to 1.28$)$ & 0.521 \\
\hline stomach & $76 / 317$ & 0.87 (0.66 to 1.15$)$ & $69 / 271$ & 0.90 (0.67 to 1.20$)$ & $94 / 404$ & 0.86 (0.67 to 1.11$)$ & $83 / 371$ & 0.85 (0.64 to 1.12$)$ & 0.167 \\
\hline Il cancers & $\begin{array}{l}3467 / \\
13935\end{array}$ & 1.01 (0.97 to 1.05$)$ & $\begin{array}{l}2752 / \\
10855\end{array}$ & $\begin{array}{c}1.02(0.98 \text { to } \\
1.07)\end{array}$ & $\begin{array}{l}3868 / \\
15708\end{array}$ & $\begin{array}{c}1.00(0.96 \text { to } \\
1.04)\end{array}$ & $\begin{array}{l}3534 / \\
14108\end{array}$ & $\begin{array}{c}1.04(1.00 \text { to } \\
1.09)\end{array}$ & 0.057 \\
\hline
\end{tabular}

\# Adjusted for Townsend quintile, body mass index, smoking status, myocardial infarction, coronary heart disease, diabetes, hypertension, stroke, rheumatoid arthritis, use of NSAIDs, Cox2-inhibitors, aspirin

† Also adjusted for family history of breast cancer, benign breast disease, use of oral contraceptives, hormone-replace therapy

\# Also adjusted for colitis and Crohn's disease

* Trend test based on number of months prescribed 
Table 4 Types of statins in cases and controls in 13 to $\mathbf{7 2}$ months prior to the index date (in cases and matched controls with at least 6 years of medical records)

\begin{tabular}{|c|c|c|c|c|c|c|c|c|c|}
\hline & & Atorvastatin & & & Pravastatin & & & Simvastatin & \\
\hline cancer & $\begin{array}{l}\text { Cases/ } \\
\text { Controls }\end{array}$ & $\begin{array}{c}\text { Adjusted Odds ratio } \\
(95 \% \mathrm{Cl})^{\#}\end{array}$ & $\begin{array}{l}P \text { - } \\
\text { value }\end{array}$ & $\begin{array}{l}\text { Cases/ } \\
\text { Controls }\end{array}$ & $\begin{array}{c}\text { Adjusted Odds ratio } \\
(95 \% \mathrm{Cl})^{\#}\end{array}$ & $\begin{array}{l}P \text { - } \\
\text { value }\end{array}$ & $\begin{array}{l}\text { Cases/ } \\
\text { Controls }\end{array}$ & $\begin{array}{c}\text { Adjusted Odds ratio } \\
(95 \% \mathrm{Cl})^{\#}\end{array}$ & $\begin{array}{l}P \text { - } \\
\text { value }\end{array}$ \\
\hline breast† & $596 / 2574$ & 0.96 (0.86 to 1.06$)$ & 0.387 & $152 / 630$ & $1.02(0.85$ to 1.23$)$ & 0.835 & $871 / 3720$ & 0.98 (0.89 to 1.07$)$ & 0.584 \\
\hline prostate & $1023 / 4398$ & 0.99 (0.91 to 1.07$)$ & 0.781 & $314 / 1182$ & 1.15 (1.00 to 1.31$)$ & 0.046 & $1668 / 6924$ & 1.05 (0.99 to 1.13$)$ & 0.117 \\
\hline colorectalf & $826 / 2934$ & 1.17 (1.07 to 1.28$)$ & 0.001 & $212 / 786$ & 1.09 (0.93 to 1.28$)$ & 0.289 & $1152 / 4783$ & 0.96 (0.88 to 1.04$)$ & 0.273 \\
\hline lung & $786 / 2912$ & 1.07 (0.97 to 1.18$)$ & 0.179 & $195 / 837$ & 0.93 (0.78 to 1.11$)$ & 0.435 & $1205 / 4588$ & 1.06 (0.97 to 1.15$)$ & 0.202 \\
\hline blood & $381 / 1653$ & 0.87 (0.77 to 0.99$)$ & 0.041 & $95 / 452$ & 0.84 (0.66 to 1.06$)$ & 0.138 & $579 / 2592$ & 0.82 (0.73 to 0.91$)$ & $\begin{array}{l}< \\
0.001\end{array}$ \\
\hline bladder & $353 / 1212$ & 1.19 (1.03 to 1.37$)$ & 0.015 & $87 / 309$ & 1.08 (0.84 to 1.40$)$ & 0.544 & $513 / 1893$ & 1.10 (0.97 to 1.25$)$ & 0.119 \\
\hline skin & $168 / 655$ & 1.03 (0.84 to 1.25$)$ & 0.805 & $43 / 178$ & 0.91 (0.64 to 1.30$)$ & 0.609 & 259/998 & $1.06(0.90$ to 1.26$)$ & 0.483 \\
\hline oesophagus & 197/846 & 0.88 (0.73 to 1.05$)$ & 0.159 & $62 / 226$ & 1.05 (0.78 to 1.42$)$ & 0.740 & 298/1222 & 0.94 (0.80 to 1.09$)$ & 0.403 \\
\hline pancreas & $143 / 557$ & $0.92(0.74$ to 1.14$)$ & 0.439 & $37 / 152$ & $0.92(0.62$ to 1.35$)$ & 0.667 & $224 / 852$ & 0.99 (0.83 to 1.20$)$ & 0.952 \\
\hline stomach & $123 / 500$ & 0.94 (0.75 to 1.18$)$ & 0.604 & $41 / 149$ & 1.03 (0.71 to 1.50$)$ & 0.880 & $186 / 819$ & 0.85 (0.70 to 1.03$)$ & 0.106 \\
\hline All cancers & $\begin{array}{l}5357 / \\
21253\end{array}$ & $1.01(0.98$ to 1.05$)$ & 0.461 & $\begin{array}{l}1442 / \\
5680\end{array}$ & $1.02(0.96$ to 1.09$)$ & 0.488 & $\begin{array}{l}8102 / \\
32769\end{array}$ & $1.00(0.97$ to 1.03$)$ & 0.844 \\
\hline
\end{tabular}

\# Adjusted for Townsend quintile, body mass index, smoking status, myocardial infarction, coronary heart disease, diabetes, hypertension, stroke, rheumatoid arthritis, use of NSAIDs, Cox2-inhibitors, aspirin

† Also adjusted for family history of breast cancer, benign breast disease, use of oral contraceptives, hormone-replace therapy

₹ Also adjusted for colitis and Crohn's disease

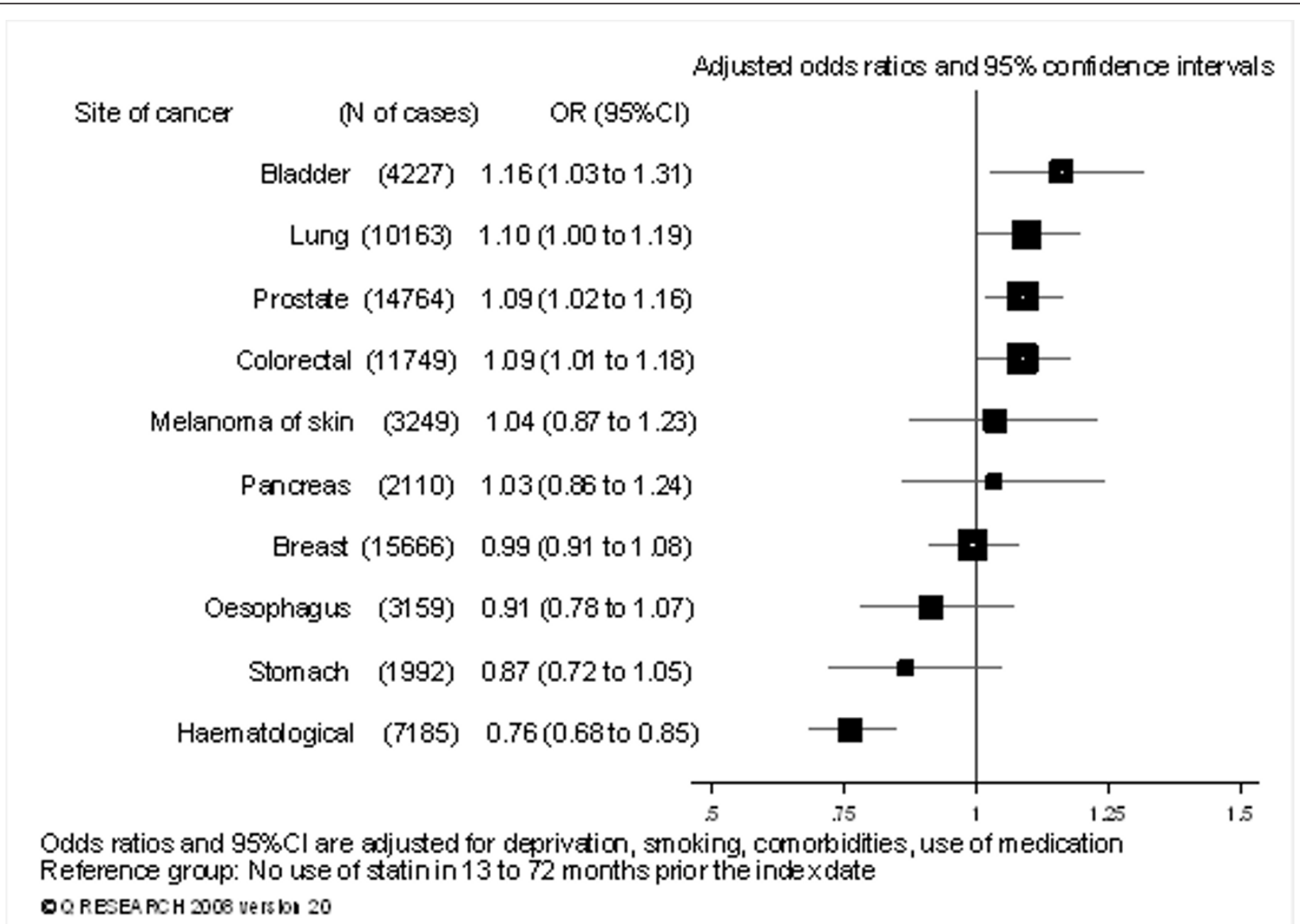

Figure 1 Risk of cancer in patients using statins for more than 365 days in 13 to 72 months prior to the index date. 
Table 5 Cumulative duration of statin use in cases and controls in 13 to 120 months prior to the index date by cancer site in cases and controls with 10 or more years of recorded data

\begin{tabular}{|c|c|c|c|c|c|c|c|c|c|c|c|}
\hline \multirow[b]{2}{*}{ cancer } & \multicolumn{2}{|c|}{ Less than 12 months } & \multicolumn{2}{|c|}{13 to 24 months } & \multicolumn{2}{|c|}{25 to 48 months } & \multicolumn{2}{|c|}{49 to 72 months } & \multicolumn{3}{|c|}{73 months and more } \\
\hline & $\begin{array}{l}\text { Cases/ } \\
\text { Controls }\end{array}$ & $\begin{array}{l}\text { Adjusted Odds } \\
\text { ratio }(95 \% \mathrm{Cl})\end{array}$ & $\begin{array}{l}\text { Cases/ } \\
\text { Controls }\end{array}$ & $\begin{array}{l}\text { Adjusted Odds } \\
\text { ratio }(95 \% \mathrm{Cl})\end{array}$ & $\begin{array}{l}\text { Cases/ } \\
\text { Controls }\end{array}$ & $\begin{array}{l}\text { Adjusted Odds } \\
\text { ratio }(95 \% \mathrm{Cl})\end{array}$ & $\begin{array}{l}\text { Cases/ } \\
\text { Controls }\end{array}$ & $\begin{array}{l}\text { Adjusted Odds } \\
\text { ratio }(95 \% \mathrm{Cl})\end{array}$ & $\begin{array}{l}\text { Cases/ } \\
\text { Controls }\end{array}$ & $\begin{array}{l}\text { Adjusted Odds } \\
\text { ratio }(95 \% \mathrm{Cl})^{\#}\end{array}$ & $\begin{array}{l}\text { P-* } \\
\text { value }\end{array}$ \\
\hline breast + & $363 / 1338$ & 1 (0.86 to 1.16$)$ & $254 / 962$ & 0.96 (0.81 to 1.15$)$ & $346 / 1208$ & $1.06(0.90$ to 1.25$)$ & $169 / 634$ & 0.93 (0.75 to 1.15$)$ & $131 / 542$ & 0.85 (0.67 to 1.08$)$ & 0.220 \\
\hline prostate & $545 / 2119$ & 0.99 (0.87 to 1.12$)$ & 489/1609 & 1.19 (1.04 to 1.36$)$ & $641 / 2424$ & 1.06 (0.94 to 1.19$)$ & 369/1394 & 1.07 (0.93 to 1.24$)$ & $320 / 1234$ & 1.12 (0.96 to 1.32$)$ & 0.173 \\
\hline colorectal $\neq$ & $446 / 1527$ & 1.06 (0.92 to 1.23$)$ & $327 / 1224$ & 1.03 (0.88 to 1.21$)$ & $429 / 1625$ & 0.97 (0.84 to 1.13 ) & $285 / 902$ & $1.20(1.01$ to 1.43$)$ & $213 / 711$ & 1.21 (0.99 to 1.48$)$ & 0.069 \\
\hline lung & $419 / 1375$ & 1.06 (0.91 to 1.25$)$ & $342 / 1064$ & 1.21 (1.01 to 1.43 ) & $458 / 1586$ & 1.05 (0.89 to 1.23$)$ & $259 / 950$ & $1.00(0.82$ to 1.21$)$ & $235 / 734$ & 1.17 (0.95 to 1.45$)$ & 0.240 \\
\hline blood & $202 / 821$ & 0.72 (0.59 to 0.88$)$ & $160 / 616$ & 0.8 (0.64 to 1.00 ) & 233/966 & 0.74 (0.61 to 0.89 ) & $133 / 468$ & 0.87 (0.68 to 1.11$)$ & $90 / 428$ & 0.55 (0.41 to 0.73$)$ & $\begin{array}{l}< \\
0.001\end{array}$ \\
\hline bladder & $172 / 565$ & 1.14 (0.91 to 1.43$)$ & $137 / 456$ & 1.19 (0.93 to 1.53$)$ & $190 / 681$ & 1.01 (0.81 to 1.26$)$ & $117 / 360$ & 1.19 (0.91 to 1.57$)$ & $94 / 280$ & $1.37(1.02$ to 1.86$)$ & 0.062 \\
\hline skin & $110 / 312$ & $1.41(1.04$ to 1.89$)$ & $56 / 270$ & 0.79 (0.55 to 1.13$)$ & $112 / 349$ & 1.21 (0.89 to 1.64$)$ & $50 / 176$ & 0.87 (0.56 to 1.36$)$ & $56 / 185$ & 1.04 (0.70 to 1.55$)$ & 0.626 \\
\hline oesophagus & $103 / 409$ & 0.9 (0.67 to 1.20$)$ & $75 / 272$ & 1.01 (0.72 to 1.42$)$ & $105 / 445$ & 0.81 (0.61 to 1.09 ) & $68 / 248$ & 1.09 (0.77 to 1.55$)$ & $59 / 185$ & 1.03 (0.70 to 1.52$)$ & 0.870 \\
\hline pancreas & $76 / 277$ & 0.89 (0.63 to 1.24$)$ & $61 / 196$ & 1.22 (0.84 to 1.78$)$ & $86 / 286$ & 0.99 (0.71 to 1.38 ) & $50 / 172$ & 1.04 (0.69 to 1.56$)$ & $40 / 148$ & 0.85 (0.53 to 1.37$)$ & 0.475 \\
\hline stomach & $58 / 232$ & 0.84 (0.58 to 1.22$)$ & $60 / 206$ & $0.82(0.56$ to 1.19$)$ & $77 / 301$ & $0.86(0.61$ to 1.21$)$ & $35 / 150$ & $0.56(0.35$ to 0.90$)$ & $38 / 165$ & 0.63 (0.39 to 1.00$)$ & 0.008 \\
\hline All cancers & $\begin{array}{l}2890 / \\
10413\end{array}$ & $0.99(0.94$ to 1.05$)$ & $\begin{array}{l}2303 / \\
8005\end{array}$ & $1.05(0.99$ to 1.11$)$ & $\begin{array}{l}3107 / \\
11437\end{array}$ & $0.98(0.93$ to 1.03$)$ & $\begin{array}{l}1776 / \\
6319\end{array}$ & 1.01 (0.95 to 1.08$)$ & $\begin{array}{l}1462 / \\
5259\end{array}$ & $1.02(0.95$ to 1.10$)$ & 0.958 \\
\hline
\end{tabular}

\# Adjusted for Townsend quintile, body mass index, smoking status, myocardial infarction, coronary heart disease, diabetes, hypertension, stroke, rheumatoid arthritis, use of NSAIDs, Cox2-inhibitors, aspirin

† Also adjusted for family history of breast cancer, benign breast disease, use of oral contraceptives, hormone-replace therapy

₹ Also adjusted for colitis and Crohn's disease

* Trend test based on number of months prescribed 
than 2 years before the index date (AOR 0.94, 95\%CI 0.62 to 1.40$)$.

The additional analysis restricted to patients with at least 10 years of medical records showed similar results, but these were not statistically significant.

\subsubsection{Lung cancer}

Although the unadjusted risk of lung cancer appeared to be significantly higher in statin users (unadjusted odds ratio (UOR) $1.16,95 \% \mathrm{CI} 1.09$ to $1.23, \mathrm{P}<0.001$ ), after adjusting for cardiovascular disease the association became much weaker (OR 1.07, 95\%CI 1.00 to $1.14, \mathrm{P}=$ 0.067 ) and did not noticeably change after further adjusting for other factors.

The unadjusted trend test for months of statin use was significant $(P<0.001)$ and use of statins for more than 4 years was associated with an increased risk of cancer (UOR 1.22 , 95\%CI 1.10 to $1.35, \mathrm{P}<0.001$ ). After adjusting for cardiovascular disease and other factors, these associations were also reduced but long-term usage remained significant (AOR 1.18, 95\%CI 1.05 to $1.34, \mathrm{P}=0.007$ ).

Analyses repeated on patients with 10 years of medical records did not show any statistically significant effect of statins for either overall or long term use.

\subsubsection{Prostate cancer}

Although the analysis demonstrated an $8 \%$ increased risk of prostate cancer for overall statin user and a $9 \%$ increased risk for patients with prescriptions covering more than a year, these associations were not statistically significant $(\mathrm{P}=0.016$ and $\mathrm{P}=0.011)$. There were no dose or duration relationships in patients with either 6 years or 10 years of medical records.

\subsubsection{Haematological malignancies}

There was a $22 \%$ reduced blood cancer risk for overall statin use (AOR 0.78, 95\%CI 0.71 to $0.86, \mathrm{P}<0.001$ ) and a $24 \%$ reduction for patients with statin prescriptions of more than a year (AOR 0.76, 95\%CI 0.68 to $0.85)$, with a significant trend for duration of use $\left(\mathrm{P}_{\text {trend }}\right.$ $<$.001). No differential effects were found for particular types of statin. Patients who stopped taking statins for more than 2 years had the same risk of cancer as nonstatin users (AOR 0.90, 95\%CI 0.67 to 1.23).

Although lymphoma, myeloma and leukaemia were similarly associated with overall use of statins and use for more an year, only leukaemia had associations with duration and dose with significant trend tests $\left(\mathrm{P}_{\text {trend }}=\right.$ 0.002 and $\mathrm{P}_{\text {trend }}<0.001$ ), a $26 \%$ risk reduction (AOR $0.74,95 \% \mathrm{CI} 0.62$ to $0.87, \mathrm{P}=0.001$ ) with at least two years of statin prescriptions, and a $25 \%$ risk reduction on high dose (AOR $0.75,95 \%$ CI 0.61 to $0.92, \mathrm{P}=0.006$ ). 4.2.7 Other cancers

There were no significant associations with statin use for any other cancers.

\subsubsection{Sensitivity analyses}

The sensitivity analyses treating missing values for smoking, and body mass index as separate categories produced very similar results. The complete case analyses resulted in very similar odds ratios, but the confidence intervals were wider due to the reduced number of observations (results available from the authors).

\section{Discussion}

In this large population-based case control study to determine the risk of common cancers associated with use of statins, we confirmed that use of statins does not affect the overall risk of cancer. We did find some evidence of an increased risk of colorectal cancer in patients using statins for 4 or more years or with a high statin dose. We also found an increased risk of bladder cancer and lung cancer in patients prescribed statins for 4 or more years. Conversely, we found a reduced risk of haematological malignancies in statin users.

There are a large number of studies devoted to statins and cancer risk summarised in meta-analyses[6-8] which did not show an adverse or protective effect of statins on the overall incidence of cancer. However, the categorisation of 'any cancer' is not a specific enough endpoint of study as it covers a range of diseases, each with a different aetiology and course of development.

Colorectal cancer, as one of the most common cancers, has been studied extensively but only eight epidemiological studies looked at the effect of long-term statin use (at least 4 years). Four of them[38-41] had odds ratios greater than unity (from 1.00 to 1.15 ) and four of them[22,42-44] reported odds ratios less than unity (from 0.71 to 0.83 ), but none of these findings reached statistically significant levels even at the $5 \%$ level. The effect of dose in our study might, however, be a replication of the effect of cumulative use because a high dose was more likely to be prescribed for patients who had been on statins for substantial period of time.

The other two most common cancers, breast and prostate, also account for a number of studies but there has been no definite outcome in associating any of these with use of statins and our null results are consistent with this. Studies for prostate cancer have been aggregated into a meta-analysis [45], which did not find any significant association with overall risk of prostate cancer and another meta-analysis[46] looking at breast cancer studies also failed to demonstrate a protective or adverse effect of statins.

For bladder cancer, results of a meta-analysis considering 5 studies showed an increased, but not significant, association between stain use and cancer risk[7]. There have been very few studies investigating the long-term 
effect of statin use on bladder cancer. One study[39] showed an increased risk for more than 5 years of statin use, which is consistent with our findings, but another very recent one found no significant association for current use of statins for more than 5 years [22]. Both studies, however, were much smaller.

Our findings of a significant increase in unadjusted lung cancer risk for statin use and for long-term use were both significantly decreased by adjusting for cardiovascular disease, but after adjusting for all factors, long-term use still showed a significant association with increased lung cancer risk. There is no causal link between cardiovascular disease and lung cancer but there is a strong association of both conditions with smoking. The finding about possible increased risk from long-term use is consistent with the results of two other studies[22,39], although their findings were not significant.

The decreased risk of haematological malignancies could be explained by reverse causality, as patients with such diagnoses are more likely to have lower lipid levels [47] although we did restrict our statin exposure to prescriptions at least 12 months before diagnosis. The effect of statins on leukaemia has been studied in vitro and there is evidence that statins might suppress the growth of promyelocitic[48] and lymphocytic[49] leukemic cells. However, no epidemiological studies have provided significant evidence of any statin effect on incidence of leukaemia.

Our study has several strengths. It is substantially larger and has greater statistical power than any previous study. This has allowed us to perform the analyses separately for different cancers within the same population. We had a substantial number of patients with at least 10 years of records, which also allowed us to examine long-term statin use. The study is based on computerrecorded prescribing and morbidity data collected prospectively. The study was not subject to response bias or recall bias as the exposure data were recorded before the date of diagnosis or pseudo-diagnosis. Any bias from misclassification is likely to be small because the level of accuracy and completeness of medical records in general practices has been shown to be high [50].

Matching the controls on sex, age, practice and calendar year removed confounding by these factors. Any bias from misclassification of statin use is likely to be minimal as more than $99 \%$ of all general practitioners' repeat prescriptions are recorded on computer[51]. We minimised the possibility of misleading data from the effects of undiagnosed cancer in new medical records by excluding prescriptions, diagnoses of co-morbidities and records of body mass index made within the 12 months prior to the date of the diagnosis or pseudo-diagnosis of cancer.

Our study has some limitations. Information on certain risk factors for cancer, such as level of physical activity, alcohol use, and diet, and information on cancer screening tests (mammography, prostate-specific antigen test and colonoscopy) were not reliably recorded on the database and not included in the analysis so there may be some residual confounding. Although we adjusted the risk of cancer for possible effects of smoking, obesity, deprivation, co-morbidities and the use of other medications, residual confounding may also result from misclassification of those variables. Values of body mass index or smoking status, were missing for about $22 \%$ of cases and $25 \%$ of controls, so we substituted missing values using multiple imputation. We did not include blood test results in the analysis, in particular high-density lipoproteins and totalserum cholesterol, because they were not consistently recorded on the data base and would be more likely to be recorded in statin users.

Although our data contain detailed information on drug prescriptions, this may not reflect actual use. However there is no reason to think that any non-adherence would systematically differ between cases and controls.

Another possible source of misclassification arises from a statin (simvastatin $10 \mathrm{mg}$ ) having become available over the counter in May 2004 in the UK, which would affect mostly younger people who are not entitled to free prescriptions [52] and only a small part of the study period. However, among statin users $81.4 \%$ of cases and $82.4 \%$ of controls were aged 65 years or older and therefore entitled to free prescribed medications. Analyses repeated on this group of patients obtained similar results, which suggests that any misclassification of use of medication because of over-the-counter purchase is not an explanation for our findings.

\section{Conclusion}

In summary, we have conducted a large populationbased case-control study that examined the effect of statins on the risk of cancer and found that there is no effect from prolonged use of statins on overall risk of cancer, but that prolonged use of statins may be associated with an increased risk of colorectal cancer, bladder cancer and lung cancer and a decreased risk of haematological malignancies.

\section{Approvals}

This project has been approved by the QRESEARCH scientific board and notified to the Trent Multi Centre Research Ethics Committee. 


\section{Funding}

There was no external funding for the study.

\section{Competing interests}

$\mathrm{JHC}$ is codirector of QResearch which is a not-for-profit partnership between the University of Nottingham and EMIS.

\section{Authors' contributions}

YV contributed to the study design, data extraction, data manipulation, data analysis, interpretation and drafting of the paper. JHC had the original idea for this study and extracted the data, contributed to the interpretation and drafting of the paper. CC contributed to the development of the idea, interpretation and drafting of the paper. YV is the guarantor of the study. All authors read and approved the final manuscript.

\section{Acknowledgements}

We acknowledge the contribution of EMIS and the University of Nottingham for expertise in creating and maintaining QRESEARCH and to the EMIS practices which contribute data without whom this research would not be possible.

Received: 5 May 2011 Accepted: 26 September 2011 Published: 26 September 2011

\section{References}

1. Scandinavian Simvastatin Survival Group: Randomised trial of cholesterol lowering in 4444 patients with coronary heart disease: the Scandinavian Simvastatin Survival Study (4S). Lancet 1994, 344:1383-1389.

2. Long-term Intervention with Pravastatin in Ischaemic Heart Disease (LIPID) Study Group: Prevention of cardiovascular events and death with pravastatin in patients with coronary heart disease and a broad range of initial cholesterol levels. NEJM 1998, 339:1349-1357.

3. Sacks FM, Pfeffer MA, Moye LA: The effects of pravastatin on coronary events after myocardial infarction in patients with average cholesterol levels. The CARE study. NEJM 1996, 335:1001-1009.

4. Heart Protection Study Collaborative Group: MRC/BHF Heart Protection Study of cholesterol lowering with simvastatin in 20,536 high risk individuals: a randomised placebo-controlled trial. Lancet 2002, 360:7-22.

5. Cannon C, Braunwald E, McCabe C, Rader D, Rouleau J, Belder R, Joyal S, Hill K, Pfeffer MA, Skene A: Comparison of intensive and moderate lipid lowering with statins after acute coronary syndromes. NEJM 2004, 350.

6. Dale K, Coleman C, Hentyan N, Kluger J, White C: Statins and cancer risk a meta-analysis. JAMA 2006, 295:74-80.

7. Kuoppala J, Lamminpää A, Pukkala E: Statins and cancer: A systematic review and meta-analysis. European journal of cancer 2008, 44:2122-2132.

8. Brugts JJ, Yetgin T, Hoeks SE, Gotto AM, Shepherd J, Westendorp RGJ, de Craen AJM, Knopp RH, Nakamura H, Ridker $P$, et al: The benefits of statins in people without established cardiovascular disease but with cardiovascular risk factors: meta-analysis of randomised controlled trials. BMJ 2009, 338:b2376.

9. John S, Schneider MP, Delles C, Jacobi J, Schmieder RE: Lipid-independent effects of statins on endothelial function and bioavailability of nitric oxide in hypercholesterolemic patients. American Heart Journal 2005, 149:473.e471-473.e410.

10. Endres M: Statins: Potential new indications in inflammatory conditions. Atherosclerosis Supplements 2006, 7:31-35.

11. Newman T, Hulley S, Task Force on Risk, Tobert J, Pahor M, Laws A, Illingworth DR, Cattley R: Carcinogenicity of Lipid-Lowering Drugs. JAMA 1996, 275:1481-1482
12. Lubet RA, Boring D, Steele VE, Ruppert JM, Juliana MM, Grubbs CJ: Lack of Efficacy of the Statins Atorvastatin and Lovastatin in Rodent Mammary Carcinogenesis. Cancer Prev Res 2009, 2:161-167.

13. Carlberg $M$, Dricu A, Blegen $H$, Wang $M$, Hjertman M, Zickert $P$, Hoog A, Larsson O: Mevalonic acid is limiting for $\mathrm{N}$-linked glycosylation and translocation of the insulin-like growth factor-1 receptor to the cell surface. Evidence for a new link between 3-hydroxy-3-methylglutarylcoenzyme a reductase and cell growth. J Biol Chem 1996, 271:17453-17462.

14. Addeo R, Altucci L, Battista T, Bonapace IM, Cancemi M, Cicatiello L, Germano D, Pacilio C, Salzano S, Bresciani F, Weisz A: Stimulation of human breast cancer MCF-7 cells with estrogen prevents cell cycle arrest by HMG-CoA reductase inhibitors. Biochemical \& Biophysical Research Communications 1996, 220:864-870.

15. Inano H, Suzuki K, Onoda M, Wakabayashi K: Anti-carcinogenic activity of simvastatin during the promotion phase of radiation-induced mammary tumorigenesis of rats. Carcinogenesis 1997, 18:1723-1727.

16. Keyomarsi $K$, Sandoval L, Band V, Pardee AB: Synchronization of tumor and normal cells from $\mathrm{G} 1$ to multiple cell cycles by lovastatin. Cancer Research 1991, 51:3602-3609.

17. Agarwal B, Bhendwal S, Halmos B, Moss SF, Ramey WG, Holt PR: Lovastatin augments apoptosis induced by chemotherapeutic agents in colon cancer cells. Clin Cancer Res 1999, 5:2223-2229.

18. Bonovas S, Filioussi K, Tsavaris N, Sitaras NM: Statins and Cancer Risk: A Literature-Based Meta-Analysis and Meta-Regression Analysis of 35 Randomized Controlled Trials. J Clin Oncol 2006, 24:4808-4817.

19. Rossebo AB, Pedersen TR, Boman K, Brudi P, Chambers JB, Egstrup K, Gerdts E, Gohlke-Barwolf C, Holme I, Kesaniemi YA, et al: Intensive Lipid Lowering with Simvastatin and Ezetimibe in Aortic Stenosis. N Engl J Med 2008, 359:1343-1356.

20. Boudreau DM, Yu O, Johnson J: Statin use and cancer risk: a comprehensive review. Expert Opinion on Drug Safety 2010, 9:603-621.

21. Flick ED, Habel LA, Chan KA, Van Den Eeden SK, Quinn VP, Haque R, Orav EJ, Seeger JD, Sadler MC, Quesenberry CP, et al: Statin Use and Risk of Prostate Cancer in the California Men's Health Study Cohort. Cancer Epidemiology Biomarkers \& Prevention 2007, 16:2218-2225.

22. Jacobs EJ, Newton CC, Thun MJ, Gapstur SM: Long-term Use of Cholesterol-Lowering Drugs and Cancer Incidence in a Large United States Cohort. Cancer Research 2011, 71:1763-1771.

23. National Statistics: Key Health Statistics from General Practice 1998: series MB6 (no 2). Office for National Statistics 2000.

24. Hippisley-Cox J, Hammersley V, Pringle M, Coupland C, Crown N, Wright L: How useful are General Practice databases for research? Analysis of their accuracy and completeness in one research network. Health Informatics Journal 2004, 10:91-109.

25. Westlake S, Office for National Statistics: Report: Cancer incidence and mortality in the United Kingdom and constituent countries, 2003-2005. HSQ 402008.

26. Valuck R, Williams S, MacArthur M, Saseen J, Nair K, McCollum M, Ensor J: A retrospective cohort study of correlates of response to pharmacologic therapy for hyperlipidemia in members of a managed care organization. Clinical Therapeuitics 2003, 25:2936-2957.

27. Stattin P, Björ O, Ferrari P, Lukanova A, Lenner P, Lindahl B, Hallmans G, Kaaks R: Prospective Study of Hyperglycemia and Cancer Risk. Diabetes Care 2007, 30:561-567.

28. Thomas E, Brewster DH, Black RJ, Macfarlane GJ: Risk of malignancy among patients with rheumatic conditions. International Journal of Cancer 2000, 88:497-502.

29. Bangalore S, Kumar S, Kjeldsen SE, Makani H, Grossman E, Wetterslev J, Gupta AK, Sever PS, Gluud C, Messerli FH: Antihypertensive drugs and risk of cancer: network meta-analyses and trial sequential analyses of 324,168 participants from randomised trials. The Lancet Oncology 2011, 12:65-82.

30. Henderson KD, Bernstein L: Etiology of Cancer: Obesity and Physical Activity. In DeVita, Hellman, and Rosenberg's cancer: Principles \& Practice of Oncology. Volume 1. Wolters Kluwer/Lippincott Williams \& Wilkins; 2008:239-244.

31. Rowan S, Office for National Statistics: Trends in cancer incidence by deprivation, England and Wales, 1990-2002. National Statistics Health Statistics Quarterly; 2007, 24-35. 
32. Gonzalez-Perez A, Garcia Rodriguez L, Lopez-Ridaura R: Effects of nonsteroidal anti-inflammatory drugs on cancer sites other than the colon and rectum: a meta-analysis. BMC Cancer 2003, 3:28.

33. Sørensen HT, Friis S, Nørgård B, Mellemkjær L, Blot WJ, McLaughlin JK, Ekbom A, Baron JA: Risk of cancer in a large cohort of nonaspirin NSAID users: a population-based study. British Journal of Cancer 2003, 88:1687-1692.

34. Heiss G, Wallace R, Anderson GL, Aragaki A, Beresford SAA, Brzyski R, Chlebowski RT, Gass M, LaCroix A, Manson JE, et al: Health Risks and Benefits 3 Years After Stopping Randomized Treatment With Estrogen and Progestin. JAMA 2008, 299:1036-1045.

35. Royston P: Multiple imputation of missing values. Stata Journal 2004 4:227-241.

36. Royston P: Multiple imputation of missing values: update of ice. The Stata Journal 2005, 5:527-536.

37. Cancer Statistics Registration 2003: series MB1 (no 34). Office for National Statistics 2005

38. Coogan P, Rosenberg $L$, Strom B: Statin use and the risk of 10 cancers Epidemiology 2007, 18:213-219.

39. Friedman GD, Flick ED, Udaltsova N, Chan J, Quesenberry CP, Habel LA: Screening statins for possible carcinogenic risk: up to 9 years of followup of 361859 recipients. Pharmacoepidemiology and Drug Safety 2008, 17:27-36.

40. Yang YX, Hennessy S, Propert K, Hwang WT, Sarkar M, Lewis JD: Chronic statin therapy and the risk of colorectal cancer. Pharmacoepidemiology and Drug Safety 2008, 17:869-876

41. Singh H, Mahmud SM, Turner D, Xue L, Demers AA, Bernstein CN: LongTerm Use of Statins and Risk of Colorectal Cancer: A Population-Based Study. Am J Gastroenterol 2009, 104:3015-3023.

42. Coogan PF, Smith J, Rosenberg L: Statin Use and Risk of Colorectal Cancer. J Natl Cancer Inst 2007, 99:32-40.

43. Hoffmeister M, Chang-Claude J, Brenner $\mathrm{H}$ : Individual and joint use of statins and low-dose aspirin and risk of colorectal cancer: A populationbased case-control study. International Journal of Cancer 2007, 121:1325-1330.

44. Flick ED, Habel LA, Chan KA, Haque R, Quinn VP, Van Den Eeden SK Sternfeld B, Orav EJ, Seeger JD, Quesenberry CPJ, Caan BJ: Statin Use and Risk of Colorectal Cancer in a Cohort of Middle-Aged Men in the US: A Prospective Cohort Study. Drugs 2009, 69:1445-1457.

45. Bonovas S, Filioussi K, Sitaras NM: Statin use and the risk of prostate cancer: A metaanalysis of 6 randomized clinical trials and 13 observational studies. International Journal of Cancer 2008, 123:899-904

46. Bonovas S, Filioussi K, Tsavaris N, Sitaras NM: Use of Statins and Breast Cancer: A Meta-Analysis of Seven Randomized Clinical Trials and Nine Observational Studies. Journal of Clinical Oncology 2005, 23:8606-8612.

47. Kuliszkiewicz-Janus M, Małecki R, Mohamed A: Lipid changes occuring in the course of hematological cancers. Cellular \&amp; Molecular Biology Letters 2008, 13:465-474.

48. Sassano A, Katsoulidis E, Antico G, Altman JK, Redig AJ, Minucci S, Tallman MS, Platanias LC: Suppressive Effects of Statins on Acute Promyelocytic Leukemia Cells. Cancer Res 2007, 67:4524-4532.

49. Chapman-Shimshoni D, Yuklea M, Radnay J, Shapiro H, Lishner M: Simvastatin induces apoptosis of B-CLL cells by activation of mitochondrial caspase 9. Experimental Hematology 2003, 31:779-783.

50. Hippisley-Cox J, Pringle M, Cater R, Wynn A, Hammersley V, Coupland C, Hapgood R, Horsfield P, Teasdale S: The electronic record in primary care regression or progression? Cross-sectional survey. BMJ 2003, 326:1439-1443.

51. Department of Health: NHS repeat dispensing schemes in England. 2007

52. Filion KB, Delaney JAC, Brophy JM, Ernst P, Suissa S: The impact of overthe-counter simvastatin on the number of statin prescriptions in the United Kingdom: a view from the General Practice Research Database. Pharmacoepidemiology and Drug Safety 2007, 16:1-4.

\section{Pre-publication history}

The pre-publication history for this paper can be accessed here: http://www.biomedcentral.com/1471-2407/11/409/prepub

doi:10.1186/1471-2407-11-409

Cite this article as: Vinogradova et al:: Exposure to statins and risk of common cancers: a series of nested case-control studies. BMC Cancer 2011 11:409.

\section{Submit your next manuscript to BioMed Central and take full advantage of:}

- Convenient online submission

- Thorough peer review

- No space constraints or color figure charges

- Immediate publication on acceptance

- Inclusion in PubMed, CAS, Scopus and Google Scholar

- Research which is freely available for redistribution

Submit your manuscript at www.biomedcentral.com/submit
C Biomed Central 